\title{
Influences of avalanche-defence snow-supporting structures on ground temperature in Alpine permafrost terrain
}

\author{
Maraia Phillips, Perry Bartelt, Marc Ghristen \\ Swiss Federal Institute for Snow and Avalanche Research, CH-7260 Davos Dorf, Switzerland
}

\begin{abstract}
To investigate the effects of steel snow-supporting structures on the thermal regime of the ground in typical Alpine permafrost avalanche terrain, ground temperatures were monitored and simulated on an avalanche slope equipped with experimental snow-supporting structures. Temperature measurements were effected in $1 \mathrm{~m}$ boreholes above and below a row of snow nets and in two $18 \mathrm{~m}$ boreholes located between the structures and in a reference location. The presence of the structures can induce modifications of the temporal and spatial snow-cover distribution, leading to differences in active-layer temperatures just below and above the structures: snow accumulates above the supporting surface of the structures, and frequently there is less snow below. The long-term thermal effect of these variations near a snow net was simulated using a twodimensional finite-element program based on heat conduction. The material and thermal characteristics of the ground simulated are obtained from temperature measurements and from borehole-core information.
\end{abstract}

\section{INTRODUCTION}

Snow-supporting structures are built in avalanche-starting areas and are designed to retain snow on steep slopes and prevent the formation of avalanches. Above $2500 \mathrm{~m}$ a.s.l., they may be located in permafrost terrain. Their design life is approximately 100 years. Expensive damage to structures located on permafrost has been induced by terrain creep and rock fall in permafrost areas (Stoffel, 1995). It has been surmised that the structures could have an effect on ground temperature in two ways: through conduction of heat into the ground from the steel supports to the underlying foundations and by modification of the distribution of the snow cover (Haefeli 1954; Keller, 1994; Stoffel, 1995). To determine the effect of steel snow-supporting structures on the thermal regime of the ground, and hence on slope stability in unconsolidated sediments containing ice, ground and structure, temperatures have been monitored for 1 year on a steep avalanche slope at $2980 \mathrm{~m}$ a.s.l. in permafrost terrain.

In this paper we focus on the effects of the modified snow cover on the ground thermal regime only. Snow-supporting structures affect snow-cover distribution in that snow is retained artificially on the slope. Snow tends to accumulate above the structure-retaining surfaces, and, as these are approximately normal to the slope, less snow accumulates below. Snow-cover gliding can occur on steep slopes, leading to the formation of a reduced snow cover below and an increase in snow depth above each row of structures. However, this phenomenon is limited to slopes with relatively smooth ground cover. Wind action can also have an effect in reducing snow depth around the supports of structures (wind scooping; see Fig. 1) or in causing the formation of snowdrifts near structures.

Snow-cover distribution strongly affects ground temperature due to the elevated insulating properties of snow. In winter, the presence of snow has a "warming" effect, pre- venting geothermal heat loss - providing the snow cover is thicker than $50 \mathrm{~cm}$ - and in summer a "cooling" effect, protecting the ground from direct solar radiation (Nicholson, 1976; Goodrich, 1982).

\section{TEST-SITE GHARACTERISTICS}

Experimental snow-supporting structures designed for technical and thermal analyses were built on a northwestoriented avalanche slope in permafrost terrain at $2980 \mathrm{~m}$ a.s.l. above Pontresina in the eastern Swiss Alps. The slope angle is $36-38^{\circ}$, and ground cover consists of scree elements of heterogeneous size on gneiss bedrock. The scree is $2-3 \mathrm{~m}$ thick and coarsens upwards. There is no vegetation or pedological soil present. According to core analyses, ground ice is limited to faults in the bedrock and to the finer scree near the bedrock, which has a volumetric ice content of $10-20 \%$. The top $1 \mathrm{~m}$ thick layer of coarse scree contains little moisture. Precipitation and snowmelt

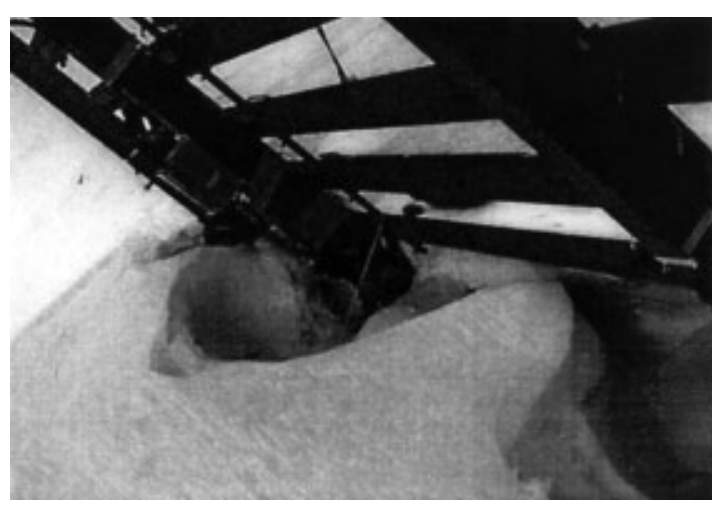

Fig. 1. Wind-scooping effect around structure supports. 


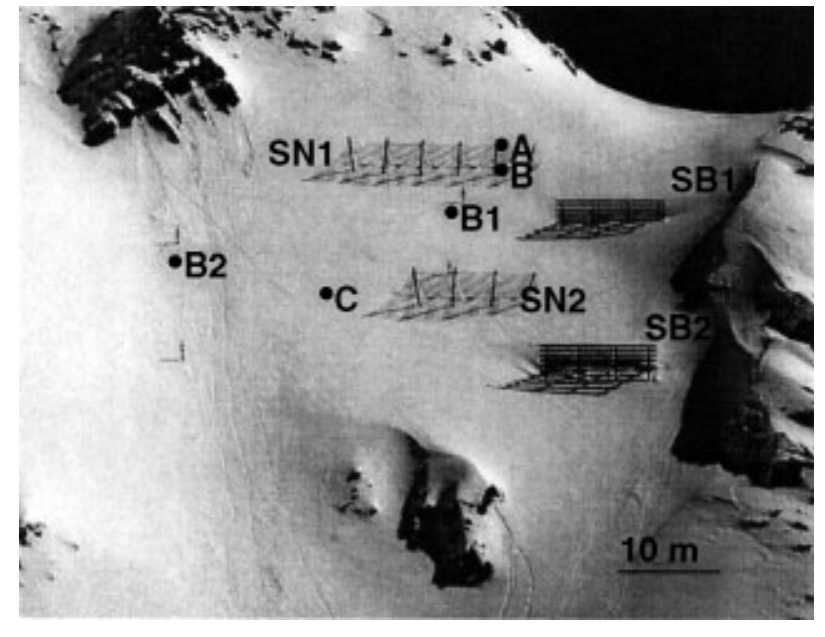

Fig. 2. Test site Pontresina-Schafberg with experimental snowsupporting structures (SN1-2: snow nets; SB1-2: snow bridges), $1 \mathrm{~m}$ boreholes $(A-C)$ and $18 \mathrm{~m}$ boreholes ( $B 1$ and $B 2$ ).

runoff are favoured by the steep gradient, by the pervious nature of the top layers of the ground and by the fact that the site is on a dip slope.

\section{MONITORING METHODS}

Snow nets, a type of snow-supporting structure well adapted to this type of terrain (Margreth, 1995), were built on the test site. Shallow $(1 \mathrm{~m})$ boreholes were drilled just above and below the snow nets (A and B in Fig. 2). Temperature is measured at 0.5 and $1 \mathrm{~m}$ depth in these boreholes using Universal Temperature Loggers (UTLs). Ground temperatures are also monitored at various depths in two $18 \mathrm{~m}$ boreholes, one of which is located between two rows of structures $(\mathrm{Bl})$ and the other in a reference location away from the influence of the structures (B2).

The $1 \mathrm{~m}$ boreholes were positioned with the aim of determining the influence of modified snow distribution at a very local scale, i.e. $1 \mathrm{~m}$ above and below the retaining surface of a snow net (boreholes A and B) as well as in a reference location (C). Data obtained in boreholes B1 and B2 were used to determine the thermal and physical characteristics of the ground to $18 \mathrm{~m}$ depth. The site was photographed four times weekly by an automatically triggered camera to allow monitoring of snow distribution and to investigate whether snow gliding creating gaps in the snow cover below structures occurs.

\section{GROUND TEMPERATURES IN BOREHOLES A-C}

Figure 3 shows the temperature evolution at $0.5 \mathrm{~m}$ depth above (A) and below (B) a snow net, as well as in the reference borehole $(\mathrm{C})$ at the same depth. The measurement period is 9 September 1997 to 6 August 1998.

During this measurement period, the snow depth on the slope never exceeded $2 \mathrm{~m}$. There were much smaller differences in snow-cover depth below and above the structures than there would have been in a winter with a snow cover of $3 \mathrm{~m}$ or more, with large amounts of snow accumulating above the structures. The differences in ground temperature above and below the structures are correspondingly small. Photographs of the site show that snow gliding causing gaps below structures did not occur during winter 1997/98. The photographs allow snow-depth monitoring at four snow stakes (Fig. 2), but very small differences in snow depth (such as occurred during the measurement period) near snowsupporting structures cannot be detected with precision. Figure 3 shows that the most significant winter temperature differences in the presence of a snow cover occurred at the coldest point of the winter (March) and at the time when the ground temperature reached $0^{\circ} \mathrm{C}$ during snowmelt. Convective warming of the ground due to infiltration of snowmelt water occurred earlier below the net and in the reference location than above the net, implying that the ground below the net was approximately $2^{\circ} \mathrm{C}$ warmer for a period of 2 weeks during the snowmelt period. This points towards a deeper snow cover above the net, particularly from March onwards.

To determine the influence of differences in snow-cover distribution on ground temperature over longer periods of time, a finite-element simulation program was used, enabling the simulation of different scenarios (e.g. a situation with a more pronounced gap in the snow below the structures in winter).

\section{SIMULATION OF GROUND TEMPERATURE WITH A FINITE-ELEMENT PROGRAM}

The program Haefeli solves the two-dimensional instationary heat-transfer equation using an implicit finite-element method. It was specially developed by the co-authors Bartelt and Christen to determine the temperature distribution in a phase-changing snowpack. Snow is treated as a three-phase (ice, water and vapour) porous medium. The program was extended to treat permafrost by introducing a fourth phase,

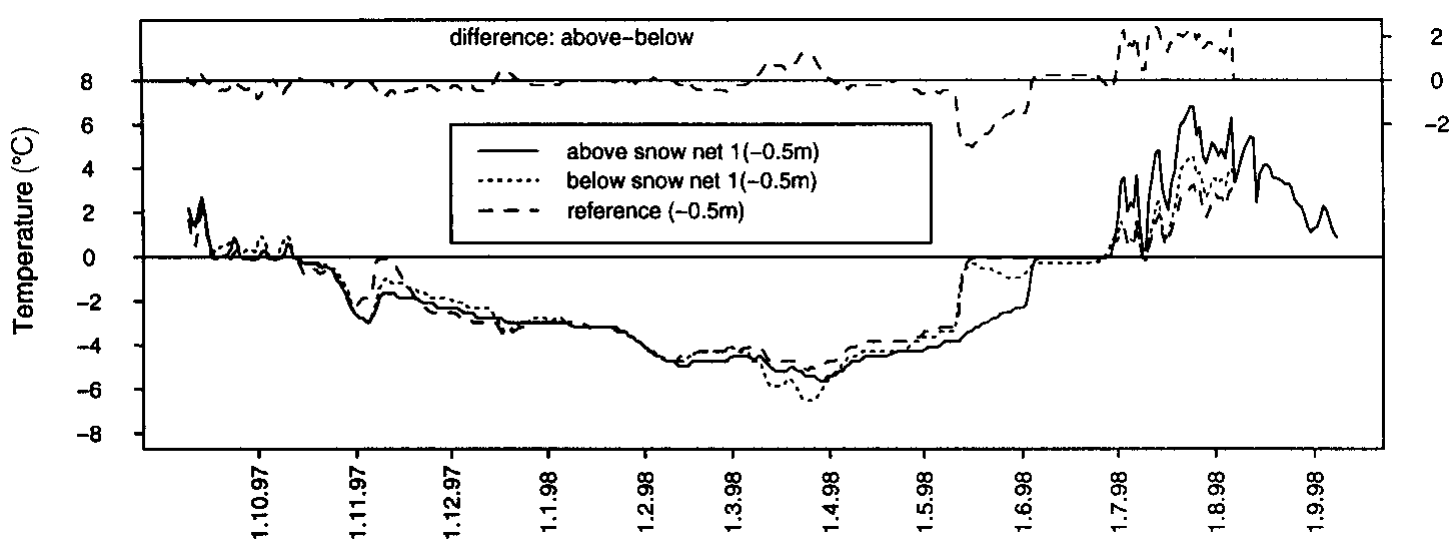

Fig. 3. Measured temperatures in boreholes A-C (9 September 1997 to 6 August 1998). The missing values for August and September 1998 have been replaced in A and B with values obtained in B2, for the purpose of computer simulations presented later. 


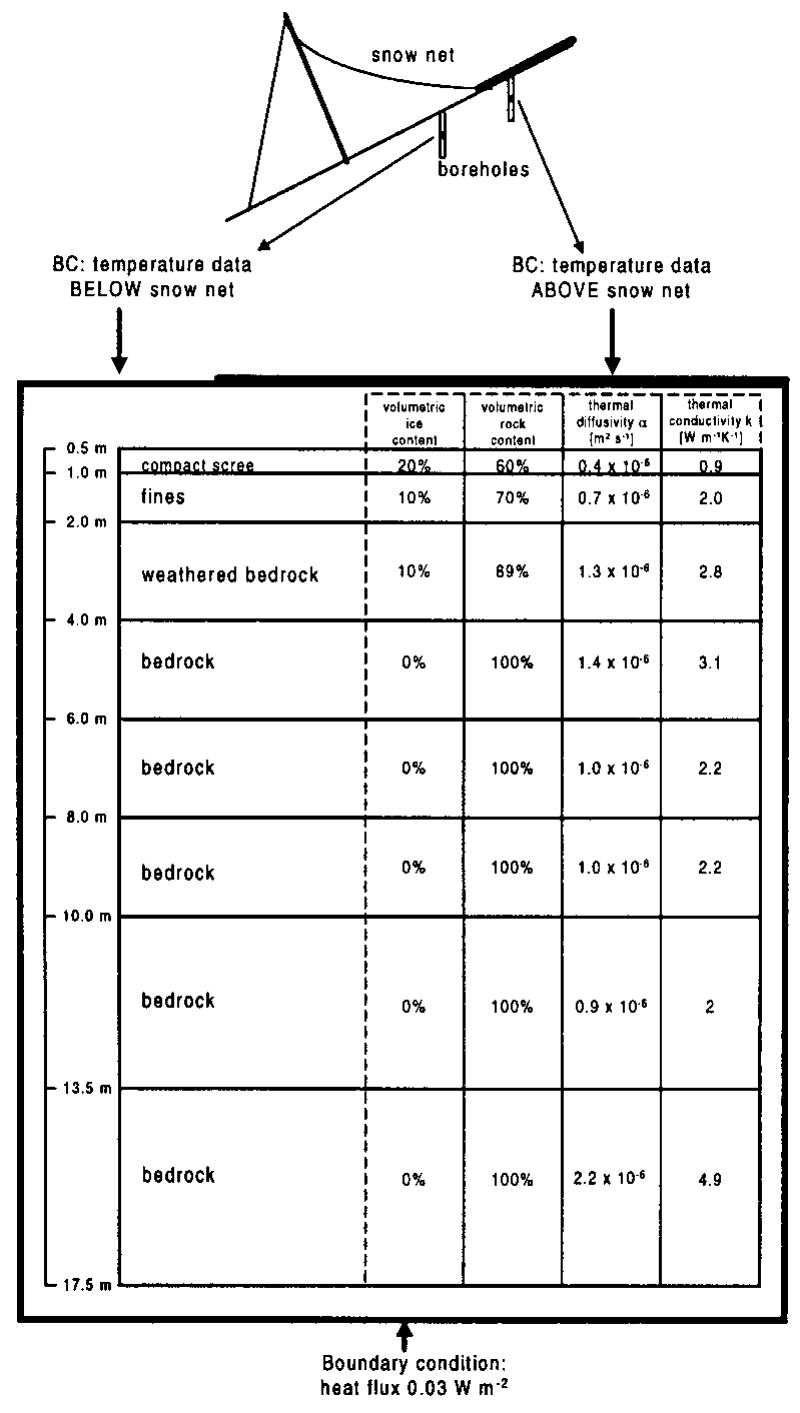

Fig. 4. Boundary conditions and ground characteristics used for simulations of temperature evolution above and below a snow net.

solid ground or rock. The thermal conductivity of both the snow and permafrost ground is determined using the volumetric contents of all phases. Both the snowpack and the permafrost ground do not deform during an analysis.

The program requires specification of the boundary conditions on all sides of the mesh, the height of the snowpack, and the various layers of ground materials. The thermophysical properties of the snow and ground components (density, thermal conductivity and specific heat capacity) must also be specified, as well as the volumetric contents of rock, air, water and ice. In the present case, temperature data obtained in the field from the boreholes are prescribed at the upper mesh boundaries. A geothermal heat flux of $0.03 \mathrm{~W} \mathrm{~m}^{-2}$ was specified for the lower boundary condition at $-17.5 \mathrm{~m}$. Phase change is taken into account by the model, which is particularly important in the active layer of permafrost where ground ice can melt in summer.

\section{GALIBRATION OF GROUND PROPERTIES}

The ground was subdivided into layers with different material and thermal characteristics (Fig. 4). Calibration of ground properties was effected using information from the $18 \mathrm{~m}$ reference borehole B2. Material characteristics of the ground are principally based on cores and observations obtained during drilling of B2. Thermal characteristics were calculated on the basis of temperature measurements. It was assumed that the density of the gneiss bedrock is $2600 \mathrm{~kg} \mathrm{~m}^{-3}$ and that its mass heat capacity is $850 \mathrm{~J} \mathrm{~kg}^{-1} \mathrm{~K}^{-1}$ (values obtained from diverse sources in the literature) for all layers except the $0.5 \mathrm{~m}$ thick layer of compact scree between -0.5 and $-1 \mathrm{~m}$, which has an assumed heat capacity of $950 \mathrm{~J} \mathrm{~kg}^{-1} \mathrm{~K}^{-1}$. The volumetric contents of air, rock and ice for each ground layer were estimated on the basis of borehole-core information.

The top $0.5 \mathrm{~m}$ thick layer of loose scree proved to be difficult to calibrate for simulation purposes: temperature measurements indicate that this material has a very high temperature gradient; contacts between the scree elements are small, reducing thermal conductivity considerably. Any heat transfer by convection (e.g. by flowing water or circulating air) is not taken into account by the program. As advised by Gold and Lachenbruch (1973), the top boundary condition in ground simulations is the measured temperature at $0.5 \mathrm{~m}$ depth, where it is assumed that conduction is the principal form of heat transfer. This avoids having to include the problematic top layer of scree and the complex ground surface, but surface information (influenced by the presence or absence of a snow cover) is still available.

Figure 5 illustrates the measured and simulated groundtemperature evolution at $-1 \mathrm{~m}$ over 1 year (data from B2). Phase change is taken into account, as water/ice is presumed to be present at this depth (Fig. 4). The most striking differences between the measured and the simulated temperature curve occur (1) during the autumn zero curtain, since the model does not take into account the presence of a humid,

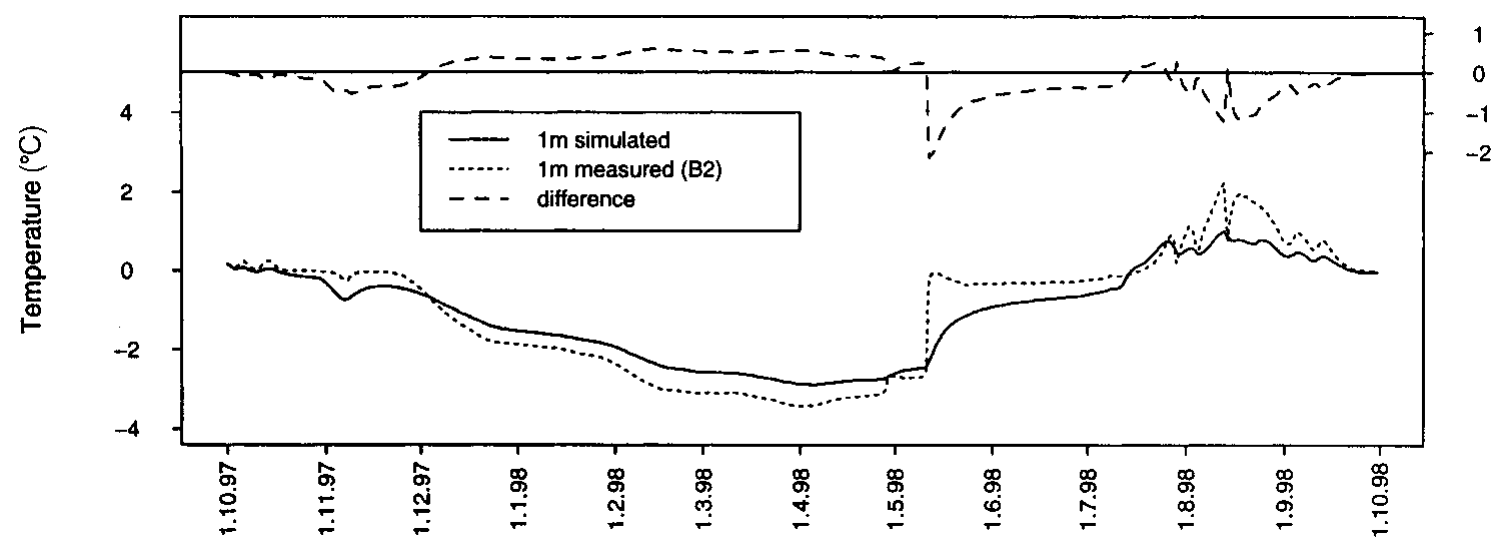

Fig. 5. Measured and simulated ground temperature evolution at $-1 \mathrm{~m}$. 


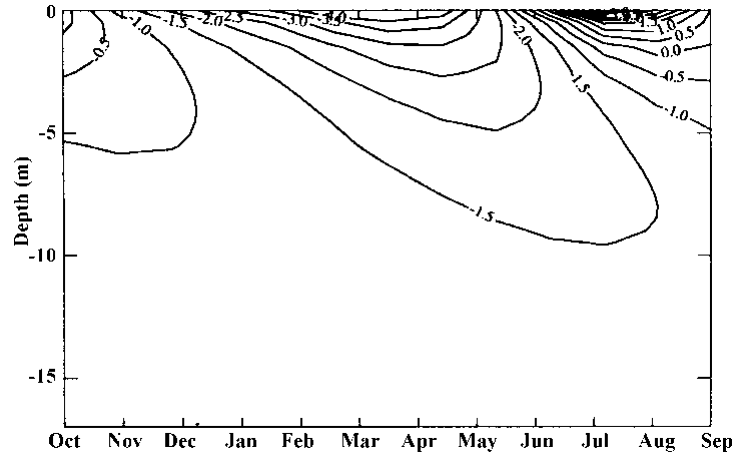

Fig. 6. Spatial and temporal ground-temperature evolution above the snow net: year 1, scenario 1.

autumn snow cover which prolongs the zero-curtain due to release of latent heat during freezing of the moisture and during snowmelt (convective warming caused by infiltration of snowmelt water is not accounted for), and (2) in summer, when convective warming also seems to occur near the ground surface (e.g. as a result of liquid precipitation).

\section{SIMULATION OF LONG-TERM EFEGTS OF A HETEROGENEOUS SNOW GOVER ABOVE AND BELOW A SNOW NET}

Two simulation scenarios using Haefeli are presented. For scenario 1 , the program is driven using measured temperature data (Fig. 3) for the upper boundary condition, whereas scenario 2 is based on the prevalence of colder temperatures below the snow net in winter.

In scenario 1, temperature data from $-0.5 \mathrm{~m}$ in boreholes $\mathrm{A}$ and $\mathrm{B}$ were used for the upper boundary conditions of the model (Fig. 4). The data from B were used for a $1 \mathrm{~m}$ segment of the upper boundary $(-0.5 \mathrm{~m})$, and the data from A were used for the remaining $3 \mathrm{~m}$ of the upper boundary, which corresponds to an approximation of the spatial distribution of the situation in the field. Average monthly temperatures over 12 months were reproduced 100 times, as the snow-supporting structures are assumed to have a design life of approximately 100 years. The effects of climatic change are not taken into account with these simulations, and climatic conditions are assumed to be those prevailing during the time of measurement. The lower boundary condition at $-17.5 \mathrm{~m}$ is a geothermal heat flux of $0.03 \mathrm{~W} \mathrm{~m}^{-2}$. The thermophysical characteristics of the ground obtained from B2 are shown in Figure 4.

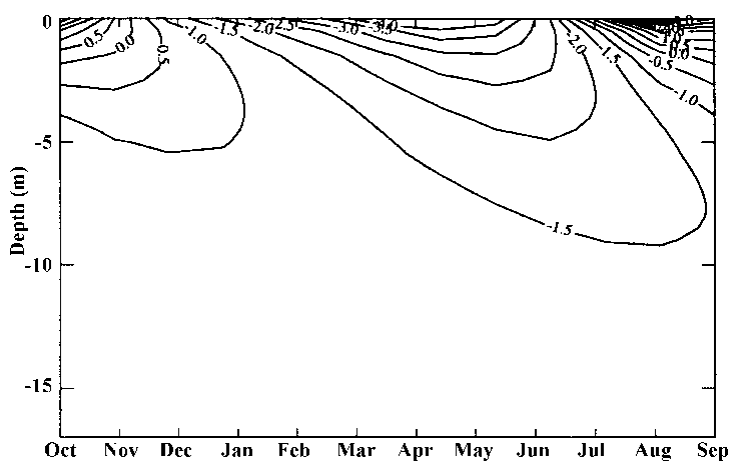

Fig. 7. Spatial and temporal ground-temperature evolution above the snow net: year 100, scenario 1.

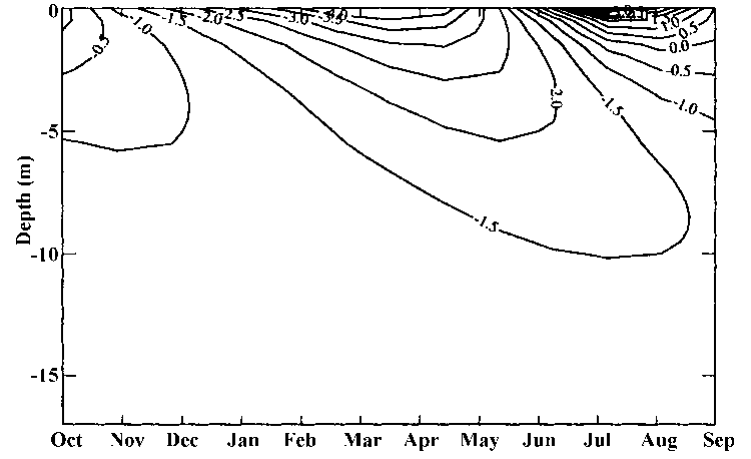

Fig. 8. Spatial and temporal ground-temperature evolution above the snow net: year 1, scenario 2.

In scenario 2 , temperatures below the net in $\mathrm{B}$ were reduced by $2^{\circ} \mathrm{C}$ in winter (i.e. between the end of the autumn zero curtain and the beginning of the spring zero curtain), in order to simulate a situation with less snow below the snow net and thus a larger difference in snow depth above and below the snow net, as would be the case on a steep slope on which snow gliding occurs. Assuming an average temperature gradient of $5^{\circ} \mathrm{Cm}^{-1}$ within the snowpack (under permafrost conditions), this would imply that there would be $40 \mathrm{~cm}$ less snow below the net than above it. All other temperatures and boundary conditions are the same as in scenario 1 .

Figures 6-9 show temperature-distribution contour plots for both scenarios, above the snow net at the start of the simulation and after a simulated time of 100 years. Plots produced for the area below the snow net are more or less identical and are not shown. The interval between the temperature contour lines is $0.5^{\circ} \mathrm{C}$.

When scenario 1 , based on measured data, is repeated over a period of 100 years, an increased phase lag becomes apparent. This implies warmer ground temperatures in early winter and colder temperatures in summer at the end of the simulation time. This can be attributed to the fact that complete snowmelt is repeatedly delayed above the snow net, causing a general lag of penetration of surface information into the ground. Using scenario 2, penetration of surface effects is delayed in the same manner, and the ground in winter also cools to a greater depth and remains colder for much longer, affecting ground temperature in summer as well. This affects not only the area of ground below the structure, but also the zone above it.

The repetition of a particular lyear situation over many

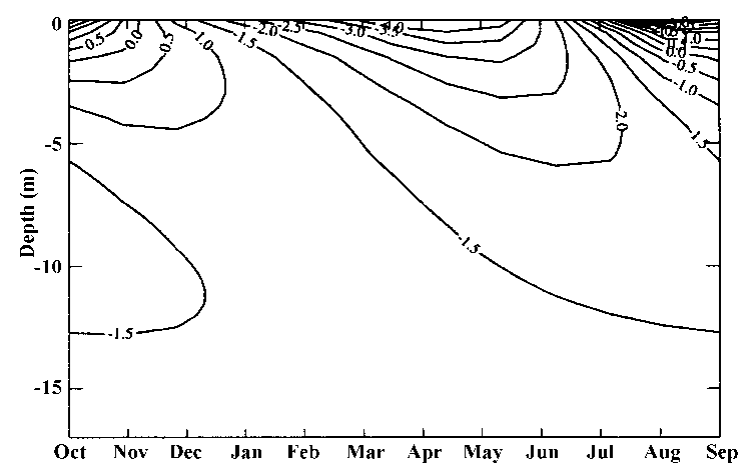

Fig. 9. Spatial and temporal ground-temperature evolution above the snow net: year 100, scenario 2. 
years is obviously not realistic, but preliminary indications of the effects of the structures on ground-temperature evolution by modification of the snow cover can already be obtained. It is necessary to continue the temperature measurements in order to obtain a longer database for further simulations.

\section{CONGLUSIONS}

Small differences in snow depth (such as those occurring on the test site during the measurement period) above and below snow-supporting structures do not lead directly to modifications of the magnitude of the ground temperature, but do change the ground-temperature distribution over time. The presence of more pronounced discrepancies in snow distribution, such as those occurring on slopes with smoother ground surfaces where snow gliding can occur or in situations with a deeper winter snow cover above the nets (induced by one or more factors), would lead to more pronounced variations of the thermal regime of the ground. In the long run, this would lead to a general decrease in ground temperature. Geotechnically problematic permafrost slopes with scree cover do not favour snow gliding due to their elevated surface roughness; the formation of large gaps in the snow cover is therefore hindered. Significant modifications of the thermal regime of the ground due to artificial modification of the temporal and spatial distribution of the snow cover by snow-supporting structures are therefore not to be expected in this type of terrain unless snowmelt is systematically delayed above structures in spring following particularly snow-rich winters.

\section{ACKNOWLEDGEMENTS}

This project is supported by the Swiss cantons Graubünden and Valais, and by the Bundesamt für Umwelt, Wald und Landschaft. Numerous people at SFISAR have been involved, and special thanks are due to W. Ammann and P. Thalparpan for the organization of the project. B. Brabec is warmly thanked for his help with figures.

\section{REFERENGES}

Gold, L. W. and A. H. Lachenbruch. 1973. Thermal conditions in permafrost: a review of North American literature. In Permafrost. Second International Conference, 13-28 July 1973, Yakutsk, U.S.S.R. North American Contribution. Washington, DC, National Academy of Sciences, 3-25.

Goodrich, L. E. 1982. The influence of snow cover on the ground thermal regime. Can. Geotech. F., 19(4), 421-432.

Haefeli, R. 1954. Fundationsprobleme des Lawinenverbaues. Mitteilungen der Versuchsanstalt für Wasserbau und Erdbau an der Eidgenössischen Technischen Hochschule in Zürich 32.

Keller, F. 1994. Interaktionen zwischen Schnee und Permafrost: eine Grundlagenstudie im Oberengadin. Eidg. Tech. Hochschule, Zürich. Versuchsanst. Wasserbau, Hydrol. Glaziol. Mitt. 127.

Margreth, S. 1995. Snow pressure measurements on snow net systems. In Sivardière, F., ed. Les apports de la recherche scientifique à la sécurité neige, glace et avalanche/The contribution of scientific research to safety with snow, ice and avalanche. Actes de Colloque, Chamonix 30 mai-3 juin 1995. Grenoble, Association Nationale pour l'Étude de la Neige et des Avalanches (ANENA), 241-248.

Nicholson, F. H. 1976. Permafrost thermal amelioration tests near Schefferville, Quebec. Can. F. Earth Sci., 13(12), 1694-1705.

Stoffel, L. 1995. Bautechnische Grundlagen für das Erstellen von Lawinenverbauungen im alpinen Permafrost. Eidg. Inst. Schnee- und Lawinenforsch. Mitt. 52. 